\title{
Epigenetics in atrial fibrillation: a reappraisal
}

Rosa Doñate Puertas, PharmD, PhD ${ }^{\mathrm{a} *}$, Rishi Arora, MD, PhD, FHRS ${ }^{\mathrm{b}}$, Sophie Rome, $\mathrm{PhD}^{\mathrm{c}}$, Babken Asatryan, MD, $\mathrm{PhD}^{\mathrm{d}}, \mathrm{H}$. Llewelyn Roderick, $\mathrm{PhD}^{\mathrm{a}, \mathrm{e} \dagger}$, Philippe Chevalier, MD, $\mathrm{PhD}^{\mathrm{f} * \dagger}$

a-Laboratory of Experimental Cardiology, Department of Cardiovascular Sciences, KU Leuven, Leuven, Belgium.

b-Feinberg Cardiovascular and Renal Research Institute, Northwestern University - Feinberg School of Medicine, Chicago, United States of America.

c-CarMeN Laboratory (UMR INSERM 1060-INRA 1397, INSA), Lyon-Sud Faculty of Medicine, University of Lyon, Pierre-Bénite, France.

d-Department of Cardiology, Inselspital, Bern University Hospital, University of Bern, Bern, Switzerland.

e-K.G. Jebsen Center for Cardiac Research, University of Oslo, Oslo, Norway.

f-Rhythmology Unit, Hospices Civils de Lyon; Université de Lyon, Lyon, France.

*Corresponding author.

${ }^{\dagger}$ Equal contribution.

Short title: Epigenetics in atrial fibrillation.

Word count: 5987.

Conflicts of interest: none.

Funding: none.

\section{Corresponding authors:}

Philippe Chevalier

Rhythmology Unit, Louis Pradel Cardiology Hospital 28 Avenue du Doyen Lépine, 69677, Bron, France.

philippe.chevalier@chu-lyon.fr

Rosa Doñate Puertas

Laboratory of Experimental Cardiology, KU Leuven,

Herestraat 49, B-3000, Leuven, Belgium

rosa.donatepuertas@kuleuven.be 


\begin{abstract}
Atrial fibrillation (AF) is the most common cardiac arrhythmia and an important cause of morbidity and mortality globally. Atrial remodeling includes changes in ion channel expression and function, structural alterations, and neural remodeling, which create an arrhythmogenic milieu resulting in AF initiation and maintenance. Current therapeutic strategies for AF involving ablation and antiarrhythmic drugs are associated with a relatively high recurrence and pro-arrhythmic side effects respectively. Over the last two decades, to overcome these issues, research has sought to identify the genetic basis for AF thereby gaining insight into the regulatory mechanisms governing its pathophysiology. Despite identification of multiple gene loci associated with AF, none have thus far led to a therapy, indicating additional contributors to pathology. Recently, in the context of expanding knowledge of the epigenome (DNA methylation, histone modifications, and noncoding RNAs), its potential involvement in the onset and progression of AF pathophysiology has started to emerge. Probing the role of various epigenetic mechanisms that contribute to AF may improve our knowledge of this complex disease, identify potential therapeutic targets and facilitate targeted therapies. Here, we provide a comprehensive review of growing epigenetic features involved in AF pathogenesis, and summarize the emerging epigenomic targets for therapy that have been explored in preclinical models of AF.
\end{abstract}

Keywords: atrial fibrillation, epigenetic, personalized therapy, systems biology, epidrug. 


\section{Introduction}

Atrial fibrillation (AF) is a common cause of mortality and morbidity, which will affect more patients with the ageing of the global population ${ }^{1}$. AF typically develops in the context of atrial myopathy ${ }^{2}$, which presents a progressive condition with continuous electrical, structural and neural remodeling of the atria. Other mechanisms such as inflammation, adipocyte infiltration, and oxidative stress play also a role in the pathogenesis of $\mathrm{AF}^{3}$. This pathophysiological remodeling of the atria, both at the tissue and cellular level, promotes arrhythmogenic mechanisms responsible for AF initiation and maintenance ${ }^{4}$. Over the last decades, a great effort has been devoted to unravel the complexity of cellular and molecular mechanisms underlying AF. Despite the significant progress in understanding pathophysiological substrates, therapies for AF have not changed substantially, as a significant proportion of patients experience a recurrence of symptoms after ablation or proarrhythmic side effects of certain drugs ${ }^{5}$.

The recent advent of systems medicine, an extension of systems biology applied to human disease ${ }^{6}$, underpins the application of a new personalized, predictive, preventive, and participatory (P4) approach to medicine $\mathrm{f}^{7}$. Although this novel approach is now being applied to cardiovascular disease in general, it remains to be implemented in $\mathrm{AF}^{8}$. Since the $\mathrm{AF}$ substrate involves a large complex of biological networks, the systems biology approach to AF will likely aid in managing this complexity and reveal novel insights into mechanisms underlying AF pathogenesis (Figure 1). This systems approach in turn requires an integrative analysis of various Omics data, including transcriptomics, proteomics, metabolomics, genomics, epigenomics, and phenomics. For example, AF-related metabolites were identified through integration of metabolic, phenomic and genomic data ${ }^{9}$. As in many other fields, the epigenome is emerging as an additional layer to the genome in regulation of gene expression underlying AF pathophysiology. Moreover, epigenetic changes during atrial remodeling are 
potential targets for therapeutic intervention in AF but they are relatively under-investigated thus far. This review focuses on assessing the relevance of epigenetic mechanisms to AF and on potential targets for epigenetic therapeutic strategies. 


\section{Epigenetic mechanisms in AF}

The epigenome is not only responsible for regulation of expression of genes during normal physiological development but is also involved in the pathophysiology of cardiovascular diseases ${ }^{10}$. Epigenetic mechanisms mediate their effect on genome activity via modulating the condensation state of chromatin and therefore the steric accessibility of DNA sequence for transcription, replication and repair, as well as by influencing association of transcriptional regulators with DNA ${ }^{11}$. DNA is packaged in the nucleus in the form of chromatin, which is made up of nucleosomes comprising 147 base pairs of DNA wrapped around an octamer histone core (two copies each of histones H2A, H2B, H3 and H4), which are then further organized into higher order structures. Chromatin is dynamic and in response to external stimuli, changes its compaction from a silent heterochromatin (associated with transcriptional repression) to an active euchromatin (where gene expression can be activated). This so-called "chromatin remodeling" is orchestrated by multiple stable and heritable epigenetic processes, including DNA methylation, histone modifications, and noncoding RNAs (ncRNAs) (Figure 2). This remodeling requires DNA- and histone-modifying enzymes, RNA molecules, and specialized ATP-dependent chromatin remodeling complexes (SWI/SNF, ISWI, CHD and INO80) ${ }^{12}$. Specifically, a series of enzymes and protein domains such as writers, erasers and readers are involved, which respectively deposit, remove and recognize epigenetic modifications of nucleotides or histone tails ${ }^{13}$.

Generally, epigenetic regulation has been explored as a modifier that explains the incomplete penetrance of certain putative disease-causing variants ${ }^{14}$. Given the pervasive nature of epigenetic regulation in human development and disease, the contribution of this process to AF pathology is likely. The following epigenetic mechanisms require further investigation due to their potentially key role in AF and as they may represent appropriate targets for future development of therapy. 


\subsection{DNA methylation associated with AF}

The importance of the epigenome in the development and progression of human disease is highlighted by association with aberrant patterns of DNA methylation ${ }^{15}$. DNA is methylated by DNA methyltransferases (DNMTs), which catalyze the transfer of a methyl group from the S-adenosyl-L-methionine to the $5^{\prime}$ carbon of cytosine most frequently located in cytosinephosphate-guanine $(\mathrm{CpG})$ islands ${ }^{16}$ (Figure 2). DNMT3a/b are de novo DNMTs capable of methylating non-methylated DNA, for example, during differentiation, whereas the maintenance DNMT1 adds a methyl group onto the daughter strand during DNA replication. DNA methylation is lost via passive and active processes involving inefficiency of maintenance mechanisms and the action of the ten-eleven translocation family dioxygenases (TETs) ${ }^{17}$ respectively (Figure 2). Methylation of DNA modulates gene expression by directly blocking transcription factor (TF) binding, or by recruiting readers such as methyl-CpG binding proteins $(\mathrm{MBPs})^{18}$.

In $\mathrm{AF}$, alterations in DNA methylation have been investigated by genome-wide profiling of whole blood in participants from the Framingham Heart Study ${ }^{19}$. Differential methylation of two $\mathrm{CpG}$ sites were found to be significantly associated with prevalent $\mathrm{AF}$, and five other CpGs were associated with incident AF. As these sites were identified in blood, whether they have a direct contribution to atrial structure or function is however unclear. In a further study of the left atrium (LA) of patients with permanent AF, 417 differentially methylated CpGs were identified that were mainly localized to gene-body and intergenic regions outside of $\mathrm{CpG}$ islands ${ }^{20}$. For those differentially methylated genes, the biological function was found to be related to inflammation, sodium and potassium transport, fibrosis and lipid metabolism.

Information regarding the importance of DNA methylation in AF may also be inferred from studies in closely related systems, for example in pathological cardiomyocyte (CM) 
remodeling. In the HL-1 atrial CM cell line, expression of the ATP-sensitive potassium channel is regulated by $\mathrm{CpG}$ methylation ${ }^{21}$. In a study of right atrial myocardial tissue from rheumatic valve disease patients, hypermethylation of the NPPA promoter, that encodes the atrial natriuretic peptide involved in cardiac remodeling, was correlated with a decrease in its expression, as well as with the increased expression of DNMT3b $\mathrm{b}^{22}$. A caveat of this study is that the analysis was performed on right atrium, whereas AF is a condition that primarily involves the LA. Linking the epigenome to PITX2, a TF identified via earlier genomic studies as being involved in AF, increases in DNMT1 and methylation of the Pitx2c promoter were reported in LA in a rat model of heart failure $(\mathrm{HF})^{23}$. In AF, we have demonstrated an association with Pitx2 promoter hypermethylation, both in human LA and in arrhythmic aging spontaneously hypertensive rats (SHRs) ${ }^{24}$. Lastly, alterations in DNA methylation are associated with the onset and progression of cardiac fibrosis ${ }^{25}$. In this regard, the expression of the tumor suppressor Rassfla, which has a well-established involvement in cardiac fibrosis, is silenced during fibroblast activation via DNMT $3 \mathrm{a}^{26}$.

The importance of DNA methylation in disease is further implicated by its use as a potential biomarker of prognosis and response to therapy in cancer ${ }^{27}$. In line with these applications in oncology, owing to its association of known AF risk factors ${ }^{28}$, aberrant DNA methylation may similarly be considered as a prognostic indicator of AF severity and progression. With regard to the role of DNA methylation in the progression of AF, its contribution remains however to be established. In particular, it is not known whether DNA methylation in LA, is causal or secondary to the pathology. Future longitudinal studies in which changes in DNA methylation are quantitated are required to determine its association with the different phenotypes of AF evolution.

\subsection{Histone modifications related to AF}


The N-terminal tails of histones are subject to an ever-increasing number of covalent and reversible post-translational modifications, including acetylation, methylation, phosphorylation, ubiquitination, among others that serve to modify chromatin compaction or to create docking sites for other transcriptional regulators ${ }^{29}$. The acetylated and methylated state of chromatin is regulated by writers such as histone acetyltransferases (HATs), and histone methyltransferases (HMTs), and erasers such as histone deacetylases (HDACs), and histone demethylases ${ }^{13}$ (Figure 2). In a manner independent of their activity on chromatin, these enzymes can also target many TFs, hormone receptors, signal transducers, chaperones and proteins of the cytoskeleton ${ }^{30}$. Recently, AF-associated risk variants were shown to fall near genes that are strongly related to structural cardiac remodeling, with regulatory features associated with the adult heart, in development of the fetal heart, or both ${ }^{31}$. These features comprised active enhancers as indicated by acetylation of histone $\mathrm{H} 3$ lysine 27 (H3K27ac) in RA and left ventricle and with mono-methylation of histone $\mathrm{H} 3$ lysine 4 (H3K4me1) and open chromatin in fetal heart tissue.

The mis-regulation of the addition or removal of acetyl groups on lysine residues of histones by HATs and HDACs respectively, has been associated with cardiovascular diseases $^{32}$ and is one of the most studied histone modifications in the AF field. The presence of acetylated histones is associated with an open, transcriptionally active chromatin ${ }^{33}$. Bromodomain and extra-terminal motif (BET) family of proteins (BRD2, BRD3, BRD4, and BRDT) can dock to these marks as readers and play a role in regulation of transcription and the cell cycle ${ }^{34}$. In human, 18 mammalian HDAC have been described, which are assigned into four classes: I, II, III and IV. Although studies into their role in AF electrophysiology are scarce, HDACs have been shown to participate in both AF onset and in progression by regulating deacetylation of cytoskeletal and contractile proteins and transcriptional reprogramming ${ }^{35}$. An association between HDAC6 and proteostasis in AF has also been 
shown $^{36}$. Moreover, HDACs control structural remodeling of the heart and contributes to cardiac fibrosis $^{25}$. In line with this effect in fibrosis, the enhancer of zeste 2 (EZH2), a HMT specific for tri-methylation of histone $\mathrm{H} 3$ lysine 27 (H3K27me3), is increased in expression in fibrotic atria and it is associated with fibroblast differentiation in AF patients ${ }^{37}$. Furthermore, HDAC3 expression and activity are increased in atrial tissue of persistent AF patients, suggesting a contribution to AF progression ${ }^{38}$.

\section{3 ncRNAs}

Recently, the identification and characterization of ncRNAs involved in AF have attracted much attention. Indeed, ncRNAs are considered potential diagnostic and prognostic biomarkers as well as therapeutic targets for $\mathrm{AF}^{39}$. ncRNAs, which can be classified based on their length, such as short-chain ncRNAs ( $<200$ nucleotides) and long ncRNA (lncRNAs), are not generally translated in proteins (Figure 2). As an emerging class of ncRNAs that differ from traditional linear RNAs, dysregulated circular RNAs (circRNAs), which act as gene regulators, have been associated with inflammatory responses in $\mathrm{AF}^{40}$. A number of studies have demonstrated that gene expression is under the control of networks of regulatory ncRNAs, which include mainly microRNAs (miRNAs) and $\operatorname{lncRNAs}{ }^{41}$. To date, over 2,000 miRNAs (20-22 nucleotides in length) have been identified in the human genome, and as high as $60 \%$ of protein-coding genes are known to be regulated by miRNAs ${ }^{42}$. The main function of miRNAs is to repress target-gene expression at the post-transcriptional level by binding to specific sites mainly within the 3 -'untranslated regions of specific mRNAs ${ }^{43}$. Recent studies have shown that changes in the miRNAs signature in patients with AF are involved in the pathophysiology of disease (Supplementary Table 1). In particular, dysregulated miRNA levels substantially contribute to the transcriptional alterations in LA from AF patients ${ }^{44}$. Interestingly, miR-1, miR-26, miR-208a, miR-328 and miR-499 are involved in cardiac electrical remodeling, causing ion channel dysregulation, resulting in 
shortening of the action potential duration and effective refractory period that promote reentry circuits ${ }^{45}$. Further, genes related to structural abnormalities are regulated by mir-21, mir26, mir-29b, mir-30, mir-133 and mir-590 ${ }^{45}$. Perturbations of a dynamic expression balance between TFs, such as PITX2, TBX5, ZFHX3, and SHOX2, and corresponding miRNAs may predispose to $\mathrm{AF}^{46}$. The possibility of the complex interaction among circRNAs, miRNAs, and mRNAs is also proposed in AF patients ${ }^{47}$. Further, the transition from paroxysmal to permanent AF involves a mechanism driven by circRNAs over miRNAs ${ }^{48}$. Finally, lncRNAs are involved in fundamental mechanisms of AF including structural remodeling, electrical remodeling, renin angiotensin system effects, and calcium handling abnormalities ${ }^{49}$. 


\section{Epigenetic therapies in AF}

Over the last decades, identification of genetic variants related to $\mathrm{AF}^{50}$ has inspired the development of novel gene therapy approaches aimed at delivering genetic material via viral or non-viral vectors into cells in order to compensate for the causative genetic alterations underlying atrial remodeling ${ }^{51}$. In particular, antiarrhythmic gene therapy approaches have been explored in preclinical large and small models of $\mathrm{AF}^{52}$. Similarly, the exploration and the identification of changes in the epigenetic landscape of AF suggests epigenetic therapies to reverse these changes. Such therapies, based on small-molecule inhibitors - the so-called epidrugs - that target and reprogram the epigenome have been widely deployed in cancer as well as in preclinical models of AF (Figure 3; Supplementary Table 2). Notable examples of the first- and second-generation of epidrugs have been approved for use in the clinic for the treatment of hematological cancers (DNMT inhibitors (DNMTis) and HDAC inhibitors (HDACis)) and other epidrugs are currently undergoing clinical trials for treatment of different forms of cancer (Figure 3). Owing in part to a lack of appropriate properties (e.g. selectivity, efficacy, toxicity) of these early generations of epidrugs, they have not been clinically implemented in AF. With the improved pharmacological profiles of new generations of epidrugs and their application ${ }^{53}$, particularly in the field of cancer ${ }^{54}$ raises the possibility however for targeting the epigenome in AF. This potential application of epidrugs is discussed below.

Inhibition of DNMTs to reverse pathological DNA methylation patterns and re-instate the transcriptional program underlying sinus rhythm has been put forward as a therapy in AF. DNMT inhibition (by DNMTis) results in loss of DNA methylation marks during DNA replication, and consequently the restoration of gene expression. The DNMTis are cytidine analogues (azacytidine, decitabine, zebularine and guadecitabine) that are incorporated into DNA, as well as non-nucleoside analogues (procainamide, hydralazine, etc.) that bind directly 
to the catalytic region of the enzyme ${ }^{55}$ (Figure 3; Supplementary Table 2). The firstgeneration of DNMTis (azacytidine and decitabine) have been shown to be clinically efficacious in the context of cancer at low doses, despite their chemical instability, toxic side effects, poor bioavailability and the lack of locus-specificity ${ }^{54}$. In support of this, we have provided a proof-of-concept that hypomethylating agents have to be considered as antiarrhythmic drugs. Specifically, chronic administration of decitabine improved ECG arrhythmic profiles as well as reduced fibrosis in the left ventricle of a SHR model of $\mathrm{AF}^{24}$. Improvement in medicinal chemistry led to the development of second-generation of DNMTi (zebularine and guadecitabine) in order to circumvent these concerns ${ }^{53,56}$. Targeting the MBPs may serve as a suitable alternative to elicit gene silencing without altering the methylation status $^{18}$ (Supplementary Table 2).

Despite the strong interest in histone-modifying enzymes as promising targets for AF treatment, the effect of their inhibition in AF is poorly explored. HDACis such as short-chain fatty acids (valproic acid), hydroxamic acids (vorinostat, belinostat, panobinostat, etc.), cyclic tetrapeptides (romidepsin), as well as benzamides (CI-994) mediate anti-tumor effects in cancer cells $^{57}$ (Figure 3; Supplementary Table 2). The first-generation of HDACis (vorinostat and romidepsin) lacked target selectivity and had unfavorable pharmacokinetic properties. These properties were later improved generating the second-generation of inhibitors (belinostat, panobinostat, CI-994, valproic acid, etc. ${ }^{53,56}$. Some of these have been shown to be also effective in preclinical cardiovascular studies, including in AF. In particular, the wellknown antiepileptic drug valproic acid, which has a good clinical tolerability, is an attractive candidate that is in clinical trials for a range of diseases. Further, in mouse studies, valproic acid attenuates atrial remodeling and delays the spontaneous onset of $\mathrm{AF}^{58}$ and in $\mathrm{HF}$, it reduces ventricular arrhythmias ${ }^{59}$. Simultaneous administration of HDACi (valproic acid, trichostatin A, and SK-7041) reverses cardiac hypertrophy in rodents ${ }^{60}$. The benzamide, CI- 
994, reduced the time of fibrillation, atrial fibrosis, intra-atrial adipocytes, and immune cell infiltration without significant effects on cardiac function during sustained AF in $\operatorname{dog}^{61}$. Moreover, a proof-of-concept shows that in vivo treatment with tubastatin A, an isoform selective inhibitor of HDAC6, protects atrial tachypaced dogs from atrial remodeling ${ }^{62}$. However, despite the positive effects of tubastatin A in preclinical studies in neurological disease, its reduced bioavailability and efficacy limit its testing in patients ${ }^{63}$. Further investigations are needed to evaluate the effects of these epidrugs and to address the underlying mechanism of action.

The third generation of epidrugs additionally involved BET inhibitors (BETis) and HMT inhibitors (Figure 3; Supplementary Table 2). BETis are emerging anticancer drugs that are now in clinical trials, such as OTX015 or I-BET762 ${ }^{64}$. Nonetheless, the seed product JQ1 has not reached the clinical trial stage due to concerns about its short half-life and broad target spectrum, thus inducing toxicity, despite its anti-fibrotic effects in HF mice ${ }^{65}$. Although not yet targeted clinically, the crucial role for the epigenome in regulating cardiac inflammation and cardiac fibroblast activation underlying cardiac fibrosis ${ }^{66}$, suggests that epidrugs could also provide an innovative approach to combat atrial fibrosis associated with AF. For example, the potential of this approach was demonstrated by the inhibition of atrial fibrosis and reduction of AF vulnerability in a mouse model of chronic angiotensin II infusion by the highly selective EZH2 inhibitor GSK126 ${ }^{37}$. This inhibitor does not however show clinical effect in cancer patients (NCT02082977), suggesting lack of activity and evidencing the need for improvement of these inhibitors.

The three generations of epidrugs described can together be considered broad reprogrammers, which generally cause large-scale changes in gene expression. The lack of an optimal pharmacological profile of some of the broad reprogrammers, such as specificity and isoform selectivity, is a drawback to be overcome for clinical success. This limitation can 
induce unintended off-target toxic effects. Recently, a new category of epidrugs, known as targeted therapies, has emerged that remain to be implemented in AF. These are used to target specific genetic defects in epigenome-modifying enzymes or to exploit synthetic lethality in specific patient subsets ${ }^{67}$. On the other hand, unlike inhibitors of histone-modifying enzymes, proteolysis targeting chimeric (PROTAC) have attracted great attention as a promising approach that can be used to regulate protein function by promoting targeted protein degradation instead of inhibition ${ }^{68}$ (Supplementary Table 2). Ongoing studies are aimed at using PROTACs to selectively degrade HDAC6 ${ }^{69}$.

Future therapeutic avenues will face new challenges. Single target therapy can be limited by potential mechanisms of drug resistance. This has been circumvented in the cancer field using a polypharmacology approach, which has already provided alternative strategies such as drug combination, multicompound medication and using single compounds that have multiple targets ${ }^{70}$. The polypharmacology approach for epidrugs is not yet developed in the AF field but is expected in next years. Additionally, further improvement in the efficacy and tolerability of epidrugs will rely on optimizing their development for single or combination therapy, and designing clinical trials exploring parameters such as dosage, scheduling and targeted delivery ${ }^{56}$. 


\section{Conclusions and future directions}

The inter-patient variability in AF patients as it is related to the phenotype and response to therapy is a major contributor to the challenges surrounding AF. As the complex mechanism of AF involving the disruption of diverse biological mechanisms hampers current effective therapy, better treatment outcomes likely require tailoring the management to individual patient's needs. To this end, we expect that single or combination therapies targeting genes and/or epigenetic features will emerge as a new personalized management approach in the near future. To facilitate this process, further studies on the role played by epigenetic features/regulators in $\mathrm{AF}$ involving integrative in vitro, in vivo and in silico approaches are required. The development of patient-specific human induced pluripotent stem cell-derived CMs (iPSC-CMs) has recently emerged as a valuable tool to unravel cellular mechanisms underlying AF as well as for pharmacologic testing - both for toxicology as well as efficacy on a patient-specific background ${ }^{71}$. Through the use of tissue engineering approaches, improved disease modeling and drug testing may be achieved by incorporation of patientspecific cells in organoids. In iPSC as well as in animal models, CRISPR/Cas9 (epi)genome editing is used to modulate gene function as well as to induce epigenetic changes thereby allowing mechanistic and preclinical studies ${ }^{72}$. In vivo application of this technology holds the promise to treat a wide range of human diseases through correcting disease-causing variants or to edit the epigenome. Optimistically, certain CRISPR/Cas9 applications will be implemented in humans in the next decade although these approaches remain ethically controversial, and the off-target effects remain to be explored.

The combination of multiple approaches based on DNA methylation, chromatin accessibility, protein-DNA interactions and 3D genome organization with functional and electrophysiological data related to AF will bring new insights (Figure 4). Integrating and analysis of these data sets using computational modeling and machine learning ${ }^{73}$ to better 
correlate epigenetic changes with AF will further advance our understanding of the role of the epigenome in controlling gene regulatory networks underlying AF and these can be specifically targeted to bring about the desired outcome. Performing these analyses in a patient-specific manner will further refine strategies for disease prediction and therapeutic intervention. Identification of relationships between genetic variants associated with AF and the epigenome may further assist in establishing the role of the epigenome in AF. Many of the available Omics studies to date have focused on analyzing bulk tissue. However, single-cell methodologies can identify the cellular cardiac landscape and transcriptional diversity at a single-cell resolution in the human heart ${ }^{74}$. For example, greater insight into the role of Pitx2 in cardiac development and left-right cellular specification was recently obtained through single-cell transcriptomics ${ }^{75}$. These single-cell data combined together in the aforementioned systems approach described above will further deepen our understanding of relationships between each AF patient and therapy (Figure 1).

Implementation of information gained through the approaches above in a patientspecific manner into clinical care to drive decision-making is likely to be the upcoming challenge, as in the cancer context ${ }^{76}$. Personalized medicine will empower clinicians with tools to improve the identification of individuals at a high risk of AF. Developing polyepigenetic risk scores may be an effective method for choosing the most suitable therapy, as shown for the prediction of AF recurrence after catheter ablation ${ }^{77}$. Further, determining a correlation between atrial tissue and blood epigenetic modifications in AF patients would enable the use of blood DNA methylation as a predictor of cardiac biological aging and disease, thereby aiding in disease prediction and therapy selection. To conclude, while targeting epigenetic mechanisms appears a promising personalized therapy, it is still in its infancy. Here, we have provided examples of proof-of-concept of current epidrugs candidates in preclinical models. However, many efforts must be directed to a successful 
polypharmacological strategy in a more cell-specific manner according to personal epigenetic profile. Ultimately, the goal should be to test the potential of these new therapeutic approaches in AF clinical trials. 


\section{Figure legends}

Figure 1: Schematic overview of the systems biology approach of AF.

Systems biology attempts to understand AF pathophysiology in an integrative manner by combining phenotype, genetic variants, epigenetics marks, transcripts, proteins, and metabolic networks. This approach will contribute to developing innovative, precision strategies for AF therapy.

Figure 2: Major epigenetic mechanisms of gene expression regulation in AF.

The growing list of epigenetic features (DNA methylation, histone modifications, and noncoding RNAs) play a role in atrial remodeling in AF patients.

BET, bromodomain and extra-terminal motif; DNMT, DNA methyltransferase; HAT, histone acetyltransferase; HDAC, histone deacetylase; MBP, methyl-CpG binding protein; TET, teneleven translocation.

\section{Figure 3: Advances in epigenetic therapy.}

A selection of currently available epidrugs which target DNA/histone-modifying enzymes. BET, bromodomain and extra-terminal motif; DNMT, DNA methyltransferase; EZH2, enhancer of zeste 2; HAT, histone acetyltransferase; HDAC, histone deacetylase; HDM, histone demethylase; HMT, histone methyltransferase.

Figure 4: Bulk- and single-cell technologies for epigenetic analysis.

A selection of the technologies used in profiling bulk- and single-cell epigenomic features of the heart. 


\section{References}

1. Kornej J, Börschel CS, Benjamin EJ, Schnabel RB. Epidemiology of Atrial Fibrillation in the 21st Century. Circ Res 2020;127:4-20.

2. Shen MJ, Arora R, Jalife J. Atrial Myopathy. JACC Basic Transl Sci 2019;4:640-654.

3. Nattel S, Heijman J, Zhou L, Dobrev D. Molecular Basis of Atrial Fibrillation Pathophysiology and Therapy. Circ Res 2020;127:51-72.

4. Wijesurendra RS, Casadei B. Mechanisms of atrial fibrillation. Heart 2019;105:18601867.

5. Calvo D, Filgueiras-Rama D, Jalife J. Mechanisms and Drug Development in Atrial Fibrillation. Pharmacol Rev 2018;70:505-525.

6. Wolkenhauer O, Auffray C, Jaster R, Steinhoff G, Dammann O. The road from systems biology to systems medicine. Pediatr Res 2013;73:502-507.

7. Trachana K, Bargaje R, Glusman G, Price ND, Huang S, Hood LE. Taking Systems Medicine to Heart. Circ Res 2018;122:1276-1289.

8. Censi F, Cianfrocca C, Purificato I. Atrial fibrillation and the 4P medicine. Ann Ist Super Sanita 2013;49:247-248.

9. Yan ZT, Huang JM, Luo WL, Liu JW, Zhou K. Combined metabolic, phenomic and genomic data to prioritize atrial fibrillation-related metabolites. Exp Ther Med 2019;17:3929-3934.

10. Prasher D, Greenway SC, Singh RB. The Impact of Epigenetics on Cardiovascular Disease. Biochem Cell Biol 2020;98:12-22.

11. Chiarella AM, Lu D, Hathaway NA. Epigenetic Control of a Local Chromatin Landscape. Int J Mol Sci 2020;21. 
12. Clapier CR, Iwasa J, Cairns BR, Peterson CL. Mechanisms of action and regulation of ATP-dependent chromatin-remodelling complexes. Nat Rev Mol Cell Biol 2017; 18:407-422.

13. Gillette TG, Hill JA. Readers, writers, and erasers: chromatin as the whiteboard of heart disease. Circ Res 2015;116:1245-1253.

14. Wright CF, West B, Tuke M, et al. Assessing the Pathogenicity, Penetrance, and Expressivity of Putative Disease-Causing Variants in a Population Setting. Am J Hum Genet 2019;104:275-286.

15. Jin Z, Liu Y. DNA methylation in human diseases. Genes Dis 2018;5:1-8.

16. Ambrosi C, Manzo M, Baubec T. Dynamics and Context-Dependent Roles of DNA Methylation. J Mol Biol 2017;429:1459-1475.

17. Wu X, Zhang Y. TET-mediated active DNA demethylation: mechanism, function and beyond. Nat Rev Genet 2017;18:517-534.

18. Mahmood N, Rabbani SA. DNA Methylation Readers and Cancer: Mechanistic and Therapeutic Applications. Front Oncol 2019;9:489.

19. Lin H, Yin X, Xie Z, et al. Methylome-wide Association Study of Atrial Fibrillation in Framingham Heart Study. Sci Rep 2017;7:40377.

20. Zhao G, Zhou J, Gao J, et al. Genome-wide DNA methylation analysis in permanent atrial fibrillation. Mol Med Rep 2017;16:5505-5514.

21. Fatima N, Schooley JF, Jr., Claycomb WC, Flagg TP. Promoter DNA methylation regulates murine SUR1 (Abcc8) and SUR2 (Abcc9) expression in HL-1 cardiomyocytes. PLoS One 2012;7:e41533.

22. Shen $\mathrm{K}, \mathrm{Tu} \mathrm{T}$, Yuan Z, et al. DNA methylation dysregulations in valvular atrial fibrillation. Clin Cardiol 2017;40:686-691. 
23. Kao $\mathrm{YH}$, Chen $\mathrm{YC}$, Chung $\mathrm{CC}$, et al. Heart failure and angiotensin II modulate atrial Pitx2c promotor methylation. Clin Exp Pharmacol Physiol 2013;40:379-384.

24. Doñate Puertas R, Meugnier E, Romestaing C, et al. Atrial fibrillation is associated with hypermethylation in human left atrium, and treatment with decitabine reduces atrial tachyarrhythmias in spontaneously hypertensive rats. Transl Res 2017;184:5767.e55.

25. Tao H, Song ZY, Ding XS, Yang JJ, Shi KH, Li J. Epigenetic signatures in cardiac fibrosis, special emphasis on DNA methylation and histone modification. Heart Fail Rev 2018;23:789-799.

26. Tao H, Yang JJ, Chen ZW, et al. DNMT3A silencing RASSF1A promotes cardiac fibrosis through upregulation of ERK1/2. Toxicology 2014;323:42-50.

27. Wouters J, Vizoso M, Martinez-Cardus A, et al. Comprehensive DNA methylation study identifies novel progression-related and prognostic markers for cutaneous melanoma. BMC Med 2017;15:101.

28. Liu CF, Tang WHW. Epigenetics in Cardiac Hypertrophy and Heart Failure. JACC Basic Transl Sci 2019;4:976-993.

29. Kouzarides T. Chromatin modifications and their function. Cell 2007;128:693-705.

30. Narita T, Weinert BT, Choudhary C. Functions and mechanisms of non-histone protein acetylation. Nat Rev Mol Cell Biol 2019;20:156-174.

31. Nielsen JB, Thorolfsdottir RB, Fritsche LG, et al. Biobank-driven genomic discovery yields new insight into atrial fibrillation biology. Nat Genet 2018;50:1234-1239.

32. Backs J, Olson EN. Control of cardiac growth by histone acetylation/deacetylation. Circ Res 2006;98:15-24. 
33. Barnes CE, English DM, Cowley SM. Acetylation \& Co: an expanding repertoire of histone acylations regulates chromatin and transcription. Essays Biochem 2019;63:97107.

34. Borck PC, Guo L-W, Plutzky J. BET Epigenetic Reader Proteins in Cardiovascular Transcriptional Programs. Circ Res 2020;126:1190-1208.

35. Brundel B, Li J, Zhang D. Role of HDACs in cardiac electropathology: Therapeutic implications for atrial fibrillation. Biochim Biophys Acta Mol Cell Res 2020;1867:118459.

36. Zhang D, Hu X, Henning RH, Brundel BJ. Keeping up the balance: role of HDACs in cardiac proteostasis and therapeutic implications for atrial fibrillation. Cardiovasc Res 2016;109:519-526.

37. Song S, Zhang R, Mo B, et al. EZH2 as a novel therapeutic target for atrial fibrosis and atrial fibrillation. J Mol Cell Cardiol 2019;135:119-133.

38. Zhang D, Hu X, Li J, et al. Converse role of class I and class IIa HDACs in the progression of atrial fibrillation. J Mol Cell Cardiol 2018;125:39-49.

39. Zhou D, Yang K, Hu J, Shi J, Hu X. Noncoding RNAs in Atrial Fibrillation: Current Status and Prospect. J Cardiovasc Pharmacol 2020;75:10-17.

40. Hu X, Chen L, Wu S, et al. Integrative Analysis Reveals Key Circular RNA in Atrial Fibrillation. Front Genet 2019;10:108.

41. Zhang $\mathrm{P}, \mathrm{Wu} \mathrm{W}$, Chen $\mathrm{Q}$, Chen $\mathrm{M}$. Non-Coding RNAs and their Integrated Networks. J Integr Bioinform 2019;16.

42. Friedman RC, Farh KK, Burge CB, Bartel DP. Most mammalian mRNAs are conserved targets of microRNAs. Genome Res 2009;19:92-105.

43. Bartel DP. MicroRNAs: target recognition and regulatory functions. Cell 2009;136:215-233. 
44. Doñate Puertas R, Jalabert A, Meugnier E, Euthine V, Chevalier P, Rome S. Analysis of the microRNA signature in left atrium from patients with valvular heart disease reveals their implications in atrial fibrillation. PLoS One 2018;13:e0196666.

45. Clauss S, Sinner MF, Kääb S, Wakili R. The Role of MicroRNAs in Antiarrhythmic Therapy for Atrial Fibrillation. Arrhythm Electrophysiol Rev 2015;4:146-155.

46. Mikhailov AT, Torrado M. Interplay between cardiac transcription factors and noncoding RNAs in predisposing to atrial fibrillation. J Mol Med (Berl) 2018;96:601-610.

47. Jiang S, Guo C, Zhang W, et al. The Integrative Regulatory Network of circRNA, microRNA, and mRNA in Atrial Fibrillation. Front Genet 2019;10:526.

48. Costa MC, Cortez-Dias N, Gabriel A, et al. circRNA-miRNA cross-talk in the transition from paroxysmal to permanent atrial fibrillation. Int J Cardiol 2019;290:134-137.

49. Babapoor-Farrokhran S, Gill D, Rasekhi RT. The role of long noncoding RNAs in atrial fibrillation. Heart Rhythm 2020;17:1043-1049.

50. Doñate Puertas R, Millat G, Ernens I, et al. Atrial Structural Remodeling Gene Variants in Patients with Atrial Fibrillation. BioMed Res Int 2018;2018:4862480.

51. McRae C, Kapoor A, Kanda P, Hibbert B, Davis DR. Systematic review of biological therapies for atrial fibrillation. Heart Rhythm 2019;16:1399-1407.

52. Trivedi A, Hoffman J, Arora R. Gene therapy for atrial fibrillation - How close to clinical implementation? Int J Cardiol 2019;296:177-183.

53. Ganesan A, Arimondo PB, Rots MG, Jeronimo C, Berdasco M. The timeline of epigenetic drug discovery: from reality to dreams. Clin Epigenetics 2019;11:174.

54. Roberti A, Valdes AF, Torrecillas R, Fraga MF, Fernandez AF. Epigenetics in cancer therapy and nanomedicine. Clin Epigenetics 2019;11:81. 
55. Pechalrieu D, Etievant C, Arimondo PB. DNA methyltransferase inhibitors in cancer: From pharmacology to translational studies. Biochem Pharmacol 2017;129:1-13.

56. Morel D, Jeffery D, Aspeslagh S, Almouzni G, Postel-Vinay S. Combining epigenetic drugs with other therapies for solid tumours - past lessons and future promise. Nat Rev Clin Oncol 2020;17:91-107.

57. Sun Y, Sun Y, Yue S, Wang Y, Lu F. Histone Deacetylase Inhibitors in Cancer Therapy. Curr Top Med Chem 2018;18:2420-2428.

58. Scholz B, Schulte JS, Hamer S, et al. HDAC (Histone Deacetylase) Inhibitor Valproic Acid Attenuates Atrial Remodeling and Delays the Onset of Atrial Fibrillation in Mice. Circ Arrhythm Electrophysiol 2019;12:e07071.

59. Chowdhury SK, Liu W, Zi M, et al. Stress-Activated Kinase Mitogen-Activated Kinase Kinase-7 Governs Epigenetics of Cardiac Repolarization for Arrhythmia Prevention. Circulation 2017;135:683-699.

60. Kee HJ, Sohn IS, Nam KI, et al. Inhibition of histone deacetylation blocks cardiac hypertrophy induced by angiotensin II infusion and aortic banding. Circulation 2006;113:51-59.

61. Seki M, LaCanna R, Powers JC, et al. Class I Histone Deacetylase Inhibition for the Treatment of Sustained Atrial Fibrillation. J Pharmacol Exp Ther 2016;358:441-449.

62. Zhang D, Wu CT, Qi X, et al. Activation of histone deacetylase-6 induces contractile dysfunction through derailment of alpha-tubulin proteostasis in experimental and human atrial fibrillation. Circulation 2014;129:346-358.

63. Reddy RG, Surineni G, Bhattacharya D, et al. Crafting Carbazole-Based Vorinostat and Tubastatin-A-like Histone Deacetylase (HDAC) Inhibitors with Potent in Vitro and in Vivo Neuroactive Functions. ACS Omega 2019;4:17279-17294. 
64. Alqahtani A, Choucair K, Ashraf M, et al. Bromodomain and extra-terminal motif inhibitors: a review of preclinical and clinical advances in cancer therapy. Future Sci OA 2019;5:Fso372.

65. Stratton MS, Bagchi RA, Felisbino MB, et al. Dynamic Chromatin Targeting of BRD4 Stimulates Cardiac Fibroblast Activation. Circ Res 2019;125:662-677.

66. Felisbino MB, McKinsey TA. Epigenetics in Cardiac Fibrosis: Emphasis on Inflammation and Fibroblast Activation. JACC Basic Transl Sci 2018;3:704-715.

67. Jones PA, Issa JP, Baylin S. Targeting the cancer epigenome for therapy. Nat Rev Genet 2016;17:630-641.

68. Sun X, Gao H, Yang Y, et al. PROTACs: great opportunities for academia and industry. Signal Transduct Target Ther 2019;4:64.

69. An Z, Lv W, Su S, Wu W, Rao Y. Developing potent PROTACs tools for selective degradation of HDAC6 protein. Protein Cell 2019;10:606-609.

70. Tomaselli D, Lucidi A, Rotili D, Mai A. Epigenetic polypharmacology: A new frontier for epi-drug discovery. Med Res Rev 2020;40:190-244.

71. Benzoni $\mathrm{P}$, Campostrini G, Landi S, et al. Human iPSC modeling of a familial form of atrial fibrillation reveals a gain of function of If and ICaL in patient-derived cardiomyocytes. Cardiovasc Res 2020;116:1147-1160.

72. van Kampen SJ, van Rooij E. CRISPR Craze to Transform Cardiac Biology. Trends Mol Med 2019;25:791-802.

73. Zhao J, Aslanidi O, Kuklik P, et al. Editorial: Recent Advances in Understanding the Basic Mechanisms of Atrial Fibrillation Using Novel Computational Approaches. Front Physiol 2019;10:1065.

74. Tucker NR, Chaffin M, Fleming SJ, et al. Transcriptional and Cellular Diversity of the Human Heart. Circulation 2020;142:466-482. 
75. Hill MC, Kadow ZA, Li L, Tran TT, Wythe JD, Martin JF. A cellular atlas of Pitx2dependent cardiac development. Development 2019;146.

76. Pineiro-Yanez E, Reboiro-Jato M, Gomez-Lopez G, et al. PanDrugs: a novel method to prioritize anticancer drug treatments according to individual genomic data. Genome Med 2018;10:41.

77. Choe WS, Kang JH, Choi EK, et al. A Genetic Risk Score for Atrial Fibrillation Predicts the Response to Catheter Ablation. Korean Circ J 2019;49:338-349. 


\section{Figure 1}

\section{SYSTEMS BIOLOGY}

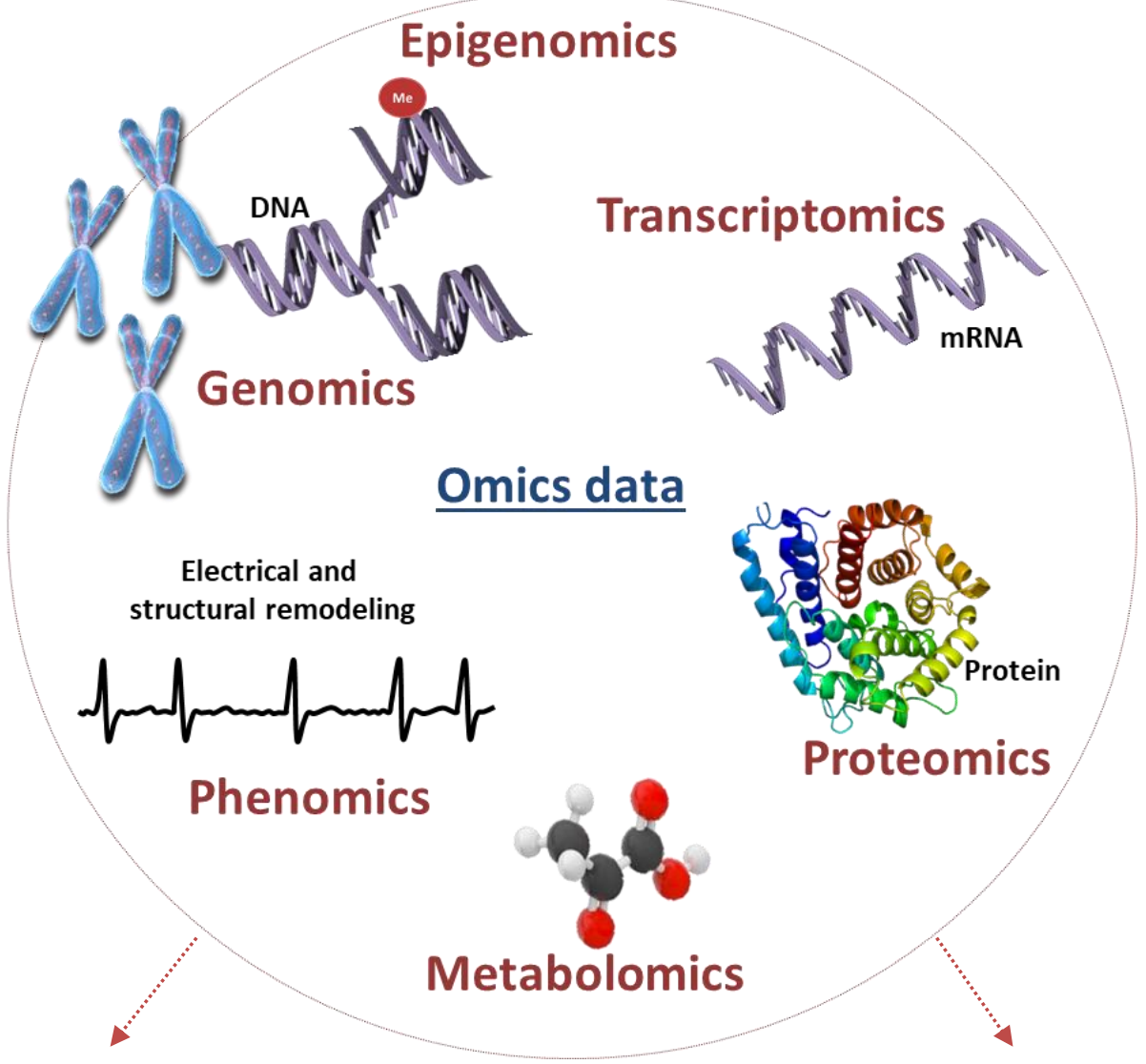

Atrial Fibrillation pathophysiology

Targeted therapy
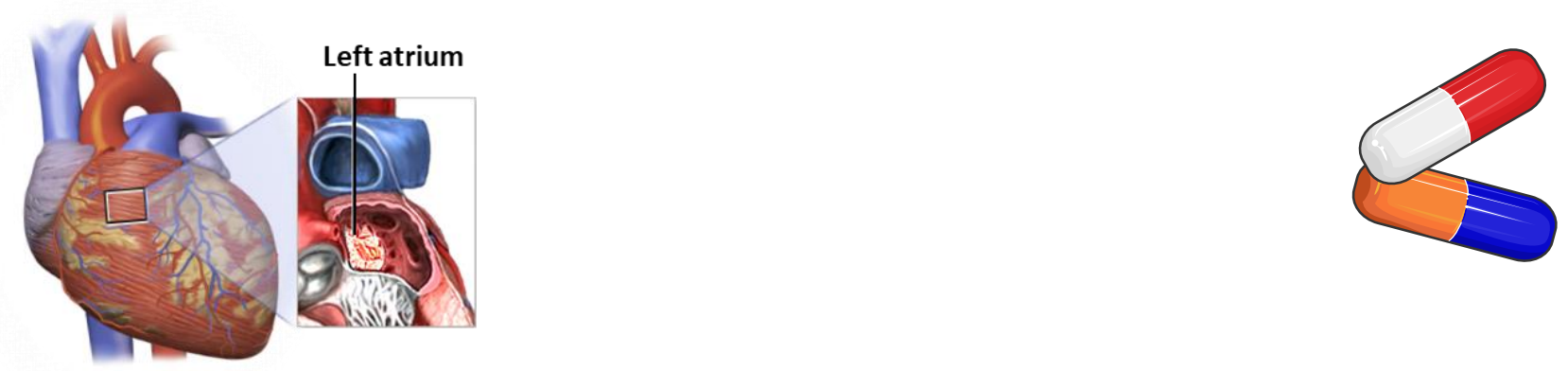


\section{Figure 2}

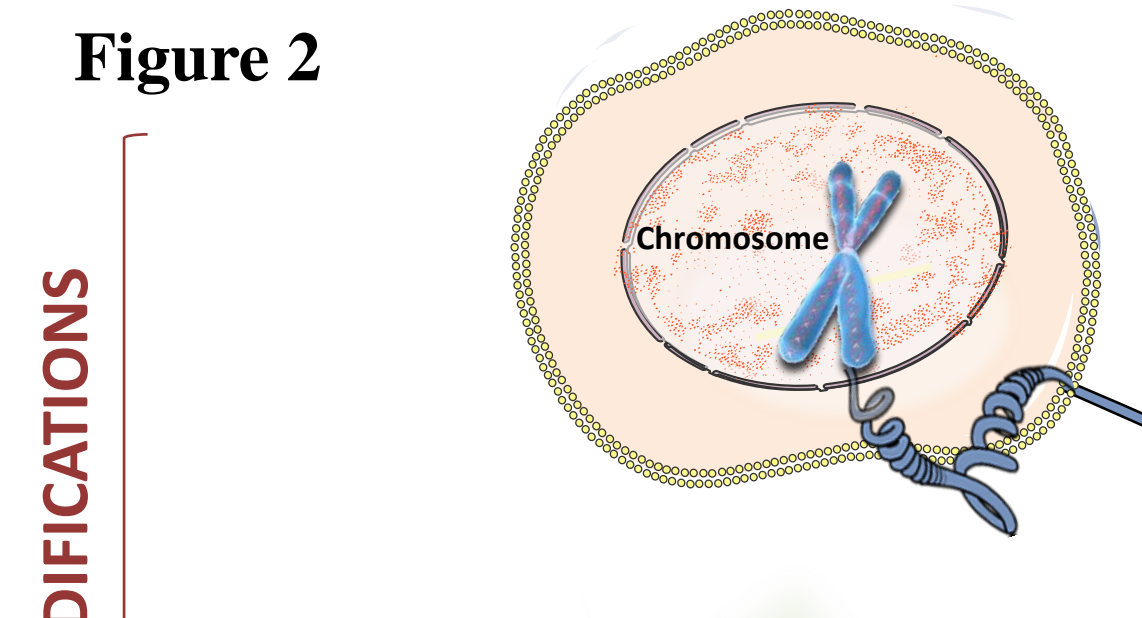
( Histone modifications 


\section{Figure 3}

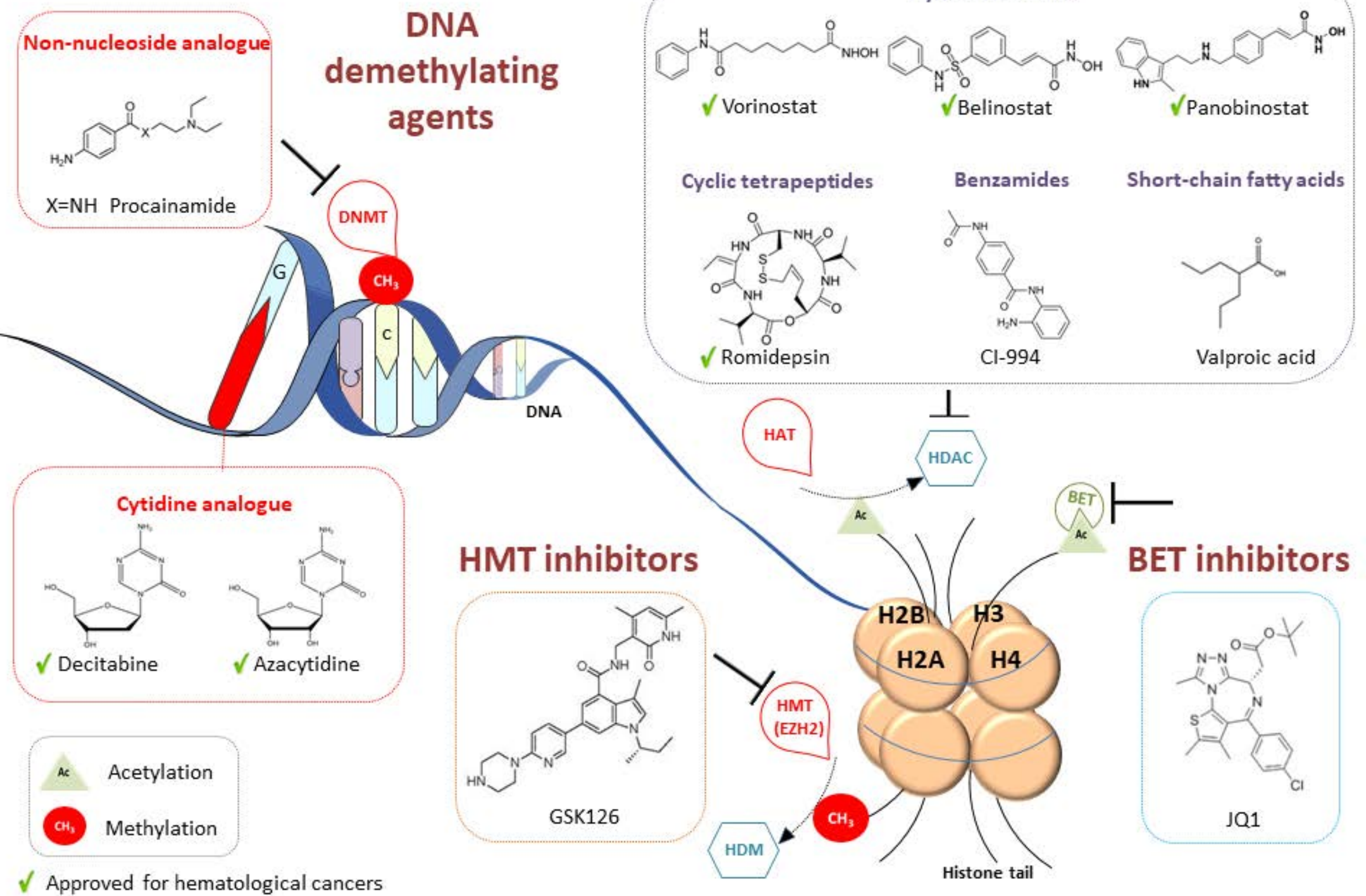




\section{Figure 4}

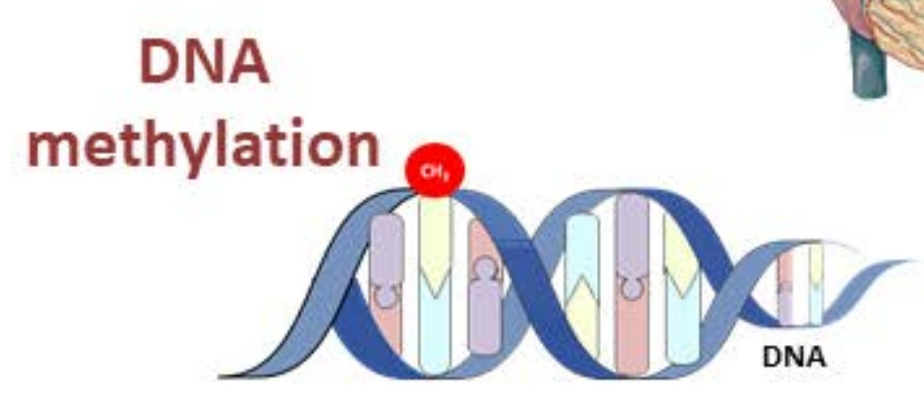

\section{Histone}

\section{modifications}

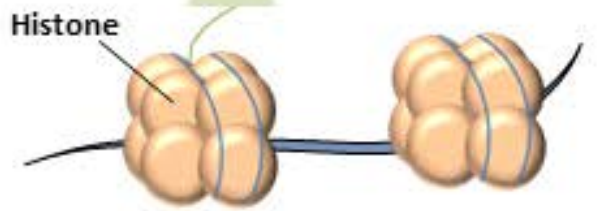

\section{Chromatin accessibility}

\section{D Genome} structure

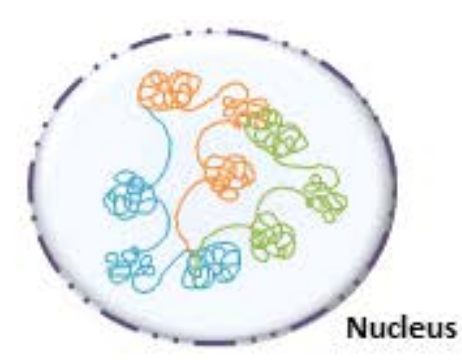

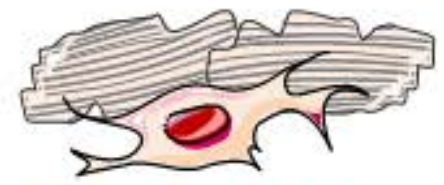

Bulk-cell methods

- Bisulfite sequencing (BS- seq)

- Reduced representation bisulfite (RRBS)

- Methylated DNA immunoprecipitation sequencing (MeDIP-seq)

- Chromatin immunoprecipitation followed by sequencing (ChIP-seq)

- Antibody-guided chromatin tagmentation sequencing (ACT- seq)

- DNase I hypersensitive site sequencing (DNase- seq)

- Assay for transposase- accessible chromatin sequencing (ATAC- seq)

- Micrococcal nuclease digestion deep sequencing (MNaseseq)

- High-throughput chromosome conformation capture ( $\mathrm{Hi}-\mathrm{C})$

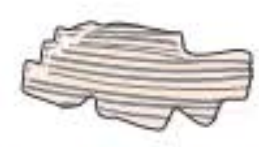

Single-cell (sc) methods

- scBS-seq

- scRRBS

- scChIP-seq

- Indexing ACT-seq

- scDNase-seq

- scATAC-seq

- scMNase-seq

- $\mathrm{scHi}-\mathrm{C}$ 


\section{Supplementary material}

Supplementary Table 1: miRNA expression profiling studies for AF.

\begin{tabular}{|c|c|c|c|c|c|}
\hline Model/tissue & Species & Control & Upregulated miRNAs & Downregulated miRNAs & References \\
\hline RA & $\begin{array}{l}\text { Patients with AF } \\
\text { undergoing cardiac } \\
\text { surgery }(n=12)\end{array}$ & $\begin{array}{l}\text { Patients without AF } \\
\text { undergoing cardiac } \\
\text { surgery }(\mathrm{n}=10)\end{array}$ & $223^{\dagger}, 328^{\dagger}, 664^{\dagger}$ & $101^{\dagger}, 320^{\dagger}, 499 \dagger$ & 1 \\
\hline RAA & $\begin{array}{l}\text { Patients with mitral } \\
\text { stenosis and AF } \\
(n=6)\end{array}$ & $\begin{array}{l}\text { Patients with mitral } \\
\text { stenosis but no AF } \\
(\mathrm{n}=4)\end{array}$ & $\begin{array}{l}188-5 \mathrm{p}, 212,335^{\dagger}, 630,1181,1202 \dagger, 1207- \\
5 \mathrm{p}, 1225-5 \mathrm{p}\end{array}$ & $\begin{array}{l}26 \mathrm{~b} \ddagger, 95,125 \mathrm{a}-5 \mathrm{p}, 125 \mathrm{~b}, 125 \mathrm{~b}-2 \ddagger, 143 \ddagger \\
145,145 \ddagger, 149,181 \mathrm{a} \dagger, 181 \mathrm{a} \neq, 181 \mathrm{~b}, \\
181 \mathrm{c} \dagger, 181 \mathrm{~d}, 324-5 \mathrm{p}, 497,500,501-5 \mathrm{p}, 550, \\
874\end{array}$ & 2 \\
\hline $\begin{array}{l}\text { LAA and RAA } \\
\text { (dysregulated } \\
\text { miRNAs were } \\
\text { detected only } \\
\text { in RA) }\end{array}$ & $\begin{array}{l}\text { Patients with } \\
\text { valvular heart } \\
\text { disease and AF } \\
(\mathrm{n}=4)\end{array}$ & $\begin{array}{l}\text { Patients with } \\
\text { valvular heart disease } \\
\text { but no } A F(n=6)\end{array}$ & $\begin{array}{l}16,21 \dagger, 21 \ddagger, 142-3 p, 142-5 \mathrm{p}, 146 \mathrm{~b}-5 \mathrm{p}^{\dagger} \\
\text { 198, 223, 224, 337-5p, 377, 483-5p, 1202, } \\
1290,1308\end{array}$ & 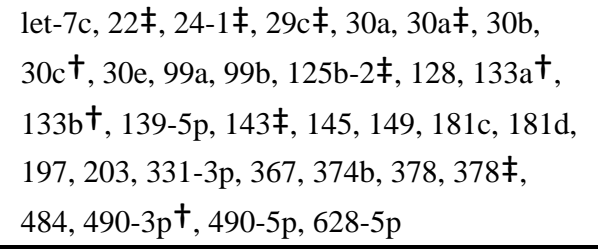 & 3 \\
\hline Plasma & $\begin{array}{l}\text { Patients with } \\
\text { paroxysmal AF } \\
\text { alone }(\mathrm{n}=5), \\
\text { patients with } \\
\text { persistent AF alone } \\
(\mathrm{n}=5)\end{array}$ & $\begin{array}{l}\text { Healthy patients } \\
(\mathrm{n}=5)\end{array}$ & \multicolumn{2}{|c|}{ miRNAs: $19 \mathrm{a}^{\dagger}, 146 \mathrm{a}^{\dagger}, 150^{\dagger}, 375^{\dagger}$} & 4 \\
\hline
\end{tabular}

RAA




\begin{tabular}{|c|c|c|c|c|c|}
\hline RAA & $\begin{array}{l}\text { Patients with } \\
\text { chronic AF } \\
\text { undergoing cardiac } \\
\text { surgery }(n=6)\end{array}$ & $\begin{array}{l}\text { Patients in sinus } \\
\text { rhythm undergoing } \\
\text { cardiac surgery } \\
(\mathrm{n}=13)\end{array}$ & 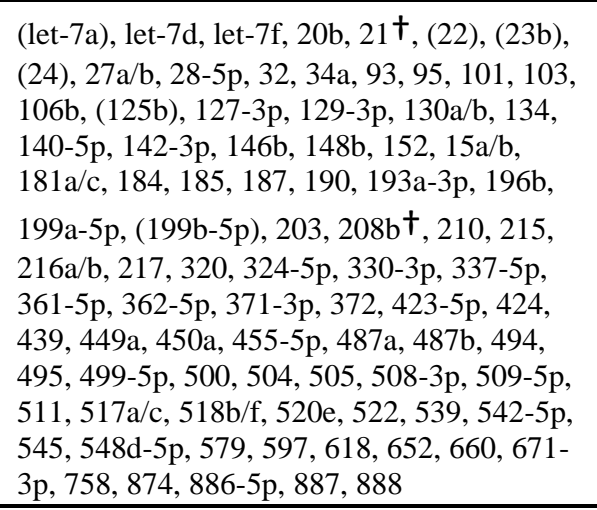 & $31,200 b, 429,885-5 p$ & 6 \\
\hline Whole blood & $\begin{array}{l}\text { Patients with AF } \\
(\mathrm{n}=150,151)\end{array}$ & $\begin{array}{l}\text { Patient in sinus } \\
\text { rhythm } \\
(\mathrm{n}=2407,2415)\end{array}$ & & $328^{\dagger}, 150-5 p$ & 7 \\
\hline LAA & $\begin{array}{l}\text { Patients with mitral } \\
\text { stenosis and AF } \\
(\mathrm{n}=6)\end{array}$ & $\begin{array}{l}\text { Patients with mitral } \\
\text { stenosis but no AF } \\
(\mathrm{n}=6)\end{array}$ & $\begin{array}{l}21-5 \mathrm{p}, 156-5 \mathrm{p}, 466^{\dagger}, 574-3 \mathrm{p}^{\dagger}, 3,178,3,196 \\
3,613-3 \mathrm{p}^{\dagger}, 4,492,4,497,4,707-5 \mathrm{p}\end{array}$ & $\begin{array}{l}\text { let-7g-5p, } 1^{\dagger}, 26 a-5 p \dagger, 26 b-5 p, 24-3 p, 29 a- \\
3 p, 151 a-5 p, 195-5 p, 361-5 p, 720,4,454 \\
5,100\end{array}$ & 8 \\
\hline $\begin{array}{l}\text { Serum, } \\
\text { platelets }\end{array}$ & $\begin{array}{l}\text { Patients with heart } \\
\text { failure and } \mathrm{AF} \\
(\mathrm{n}=15)\end{array}$ & $\begin{array}{l}\text { Patients with heart } \\
\text { failure but no AF } \\
(\mathrm{n}=26)\end{array}$ & & $150^{\dagger}$ & 9 \\
\hline LAA and RAA & $\begin{array}{l}\text { Patients with } A F \\
\text { and rheumatic } \\
\text { mitral valve } \\
\text { disease }(n=10)\end{array}$ & $\begin{array}{l}\text { Patients in sinus } \\
\text { rhythm and } \\
\text { rheumatic mitral } \\
\text { valve disease }(n=8)\end{array}$ & $\begin{array}{l}R A A, 4687-3 p, 4485,4484 \dagger, 762,3940-5 p \\
149-3 p, 4707-5 p, 4281,574-5 p, 1281,3141 \\
\text { 4488, 1973, 4463, 4505, 4466, 940, 4459, } \\
\text { 2861, 4534, 3656, 4530, 4443, 4284, 4508, } \\
\text { 1915-3p, 4298, and 4497. LAA, 3613-3p } \\
\text { 494†, 3591-3p, 4485, 574-3p, 466, 4492, } \\
\text { let-7d-3p, 4707-5p, 4534, 3940-5p, 3178, } \\
\text { 15b-5p, 21-5p, 3196, 1307-3p, 331-3p, 149- } \\
\text { 3p, 181a-5p, 30a-5p, 1973, 4497 }\end{array}$ & 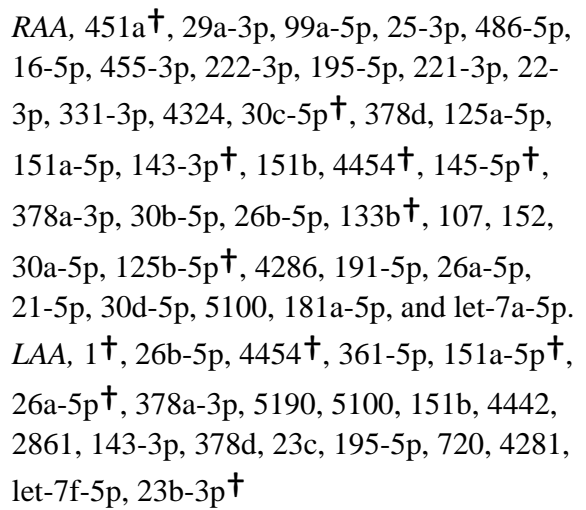 & 10 \\
\hline
\end{tabular}




\begin{tabular}{|c|c|c|c|c|c|}
\hline LAA and RAA & $\begin{array}{l}\text { Patients with AF } \\
\text { undergoing cardiac } \\
\text { surgery }(n=20)\end{array}$ & $\begin{array}{l}\text { Patients in sinus } \\
\text { rhythm undergoing } \\
\text { cardiac surgery (RA } \\
\mathrm{n}=12 ; \text { LA } \mathrm{n}=8 \text { ) }\end{array}$ & $\begin{array}{l}R A, 15 \mathrm{~b}^{\dagger}, 106 \mathrm{~b}^{\dagger}, 144 \dagger, 451^{\dagger} . L A, 18 \mathrm{a}^{\dagger}, \\
18 \mathrm{~b}^{\dagger}, 19 \mathrm{a}^{\dagger}, 19 \mathrm{~b}^{\dagger}, 23 \mathrm{a}^{\dagger}, 25 \dagger, 30 \mathrm{a}^{\dagger}, 93 \dagger \\
106 \mathrm{a}^{\dagger}, 106 \mathrm{~b}^{\dagger}, 144^{\dagger}, 363^{\dagger}, 451^{\dagger}, 486-5 \mathrm{p}^{\dagger} \\
590-5 \mathrm{p}^{\dagger}\end{array}$ & $208 \mathrm{a}^{\dagger}$ & 11 \\
\hline LAA and RAA & $\begin{array}{l}\text { Patients with AF } \\
\text { undergoing cardiac } \\
\text { surgery }(n=21)\end{array}$ & $\begin{array}{l}\text { Patients in sinus } \\
\text { rhythm undergoing } \\
\text { cardiac surgery } \\
(\mathrm{n}=16)\end{array}$ & $\begin{array}{l}\text { LA vs } R A \text { (FA and sinus rhythm), } 10 \mathrm{~b}^{\dagger}, \\
133 \mathrm{a}^{\dagger}, 133 \mathrm{~b}^{\dagger}, 30 \mathrm{~b}^{\dagger} . \text { RA vs } L A(F A), 1^{\dagger}, \\
208 \mathrm{a}^{\dagger}\end{array}$ & $\begin{array}{l}\text { LA vs RA (FA and sinus rhythm), 100†, } \\
146 \mathrm{a}^{\dagger}, 155^{\dagger}, 199 \mathrm{a}-5 \mathrm{p}^{\dagger}, 208 \mathrm{~b}^{\dagger} . \text { RA vs } L A \\
(F A), 125 \mathrm{~b}^{\dagger}, 142-5 \mathrm{p}^{\dagger}, 92 \mathrm{~b}^{\dagger} . \text { LA (sinus } \\
\text { rhythm), } 93^{\dagger}\end{array}$ & 12 \\
\hline $\begin{array}{l}\text { Plasma, atrial } \\
\text { tissue }\end{array}$ & $\begin{array}{l}\text { Patients with AF } \\
\text { undergoing cardiac } \\
\text { surgery }(n=12)\end{array}$ & $\begin{array}{l}\text { Patients in sinus } \\
\text { rhythm undergoing } \\
\text { cardiac surgery } \\
(\mathrm{n}=19)\end{array}$ & & Plasma, $21^{\dagger}, 150^{\dagger}$. Atrial tissue, $21^{\dagger}$ & 13 \\
\hline Plasma & $\begin{array}{l}\text { Patients with AF } \\
(\mathrm{n}=112)\end{array}$ & $\begin{array}{l}\text { Patients non- } \mathrm{AF}(\mathrm{n}= \\
112)\end{array}$ & $634,664,9,152,19,454,146,374 \mathrm{a}$ & $328,145,222,162,432,493 \mathrm{~b}, 1^{\dagger}$ & 14 \\
\hline LAA & $\begin{array}{l}\text { Patients with } \\
\text { nonvalvular } \\
\text { paroxysmal } \mathrm{AF}(\mathrm{n}= \\
\text { 8) }\end{array}$ & $\begin{array}{l}\text { Healthy patients } \\
(\mathrm{n}=5)\end{array}$ & $\begin{array}{l}155^{\dagger}, 146 \mathrm{~b}-5 \mathrm{p}^{\dagger}, 19 \mathrm{~b}^{\dagger}, 142-3 \mathrm{p}^{\dagger}, 486-5 \mathrm{p}^{\dagger} \\
223^{\dagger}, 193 \mathrm{~b}^{\dagger}, 519 \mathrm{~b}-3 \mathrm{p}^{\dagger}, 301 \mathrm{~b}^{\dagger}\end{array}$ & $193 a-5 p^{\dagger}$ & 15 \\
\hline $\begin{array}{l}\text { LA or } \\
\text { pulmonary } \\
\text { veins-LA } \\
\text { junctions }\end{array}$ & $\begin{array}{l}\text { Patients with AF } \\
\text { undergoing cardiac } \\
\text { surgery for valve } \\
\text { repair }(n=4)\end{array}$ & $\begin{array}{l}\text { Patients in sinus } \\
\text { rhythm undergoing } \\
\text { cardiac surgery for } \\
\text { valve repair }(n=4)\end{array}$ & $\begin{array}{l}\text { let-7a-5p, let-7c-5p, 125b-5p, 142-3p, 142- } \\
\text { 5p, 148b-3p, 15b-5p, 18a-5p, 199a-3p, } \\
199 a-5 p, 21-5 p, 21-3 p, 214-5 p, 217,25-3 p \\
324-5 p, 34 a-5 p, 451 a, 532-3 p, 576-3 p\end{array}$ & $\begin{array}{l}126-5 p, 133 a-5 p, 137,30 a-3 p, 30 e-5 p, 30 e- \\
3 p, 378 a-3 p, 409-3 p, 425-3 p, 454-3 p, 491- \\
\text { 5p, 512-3p, 517a-3p, 517c-3p, 519a-3p, } \\
\text { 519b-3p, 520c-3p, 526b-3p, 589-3p, 628-3p } \\
\text { 628-5p, 7-2-3p }\end{array}$ & 16 \\
\hline Serum & $\begin{array}{l}\text { Patients with } \mathrm{AF} \\
\text { recurrence }(\mathrm{n}=8) \\
\text { after AF ablation }\end{array}$ & $\begin{array}{l}\text { Patients without } \mathrm{AF} \\
\text { recurrence }(\mathrm{n}=11) \\
\text { after } \mathrm{AF} \text { ablation }\end{array}$ & 574-3p, 551a, 339-5p, 145-5p, 326 & $\begin{array}{l}184,183-5 p, 182-5 p, 484,32-5 p, 92 b-3 p \\
1224-5 p, 92 a-3 p, 451 a, 107,375,22-3 p \\
203 a, 548 d-5 p, 3158-3 p, 16-2-3 p, 141-3 p \\
423-5 p, 144-3 p, 486-3 p, 18 a-3 p, 1180-3 p \\
1299,196 b-5 p, 215-5 p, 1246,363-3 p, 21- \\
5 p, 1294\end{array}$ & 17 \\
\hline
\end{tabular}

Bracketed miRNAs indicate dysregulated miRNAs that lacked statistically significant changes on subsequent qPCR measurement. $\dagger$ miRNAs that were significantly altered according to qPCR analysis. $\$$ miRNA antisense. AF, atrial fibrillation; LA, left atrium; LAA, left atrial appendage; miRNA, microRNA; RA, right atrium; RAA, right atrial appendage. 
Supplementary Table 2: An overview of a selection of different classes of epidrugs with potential therapeutic application in AF. Most of these epidrugs are used in clinical practice or in ongoing clinical trials for other diseases such as cancer but remain to be using in the clinic for AF.

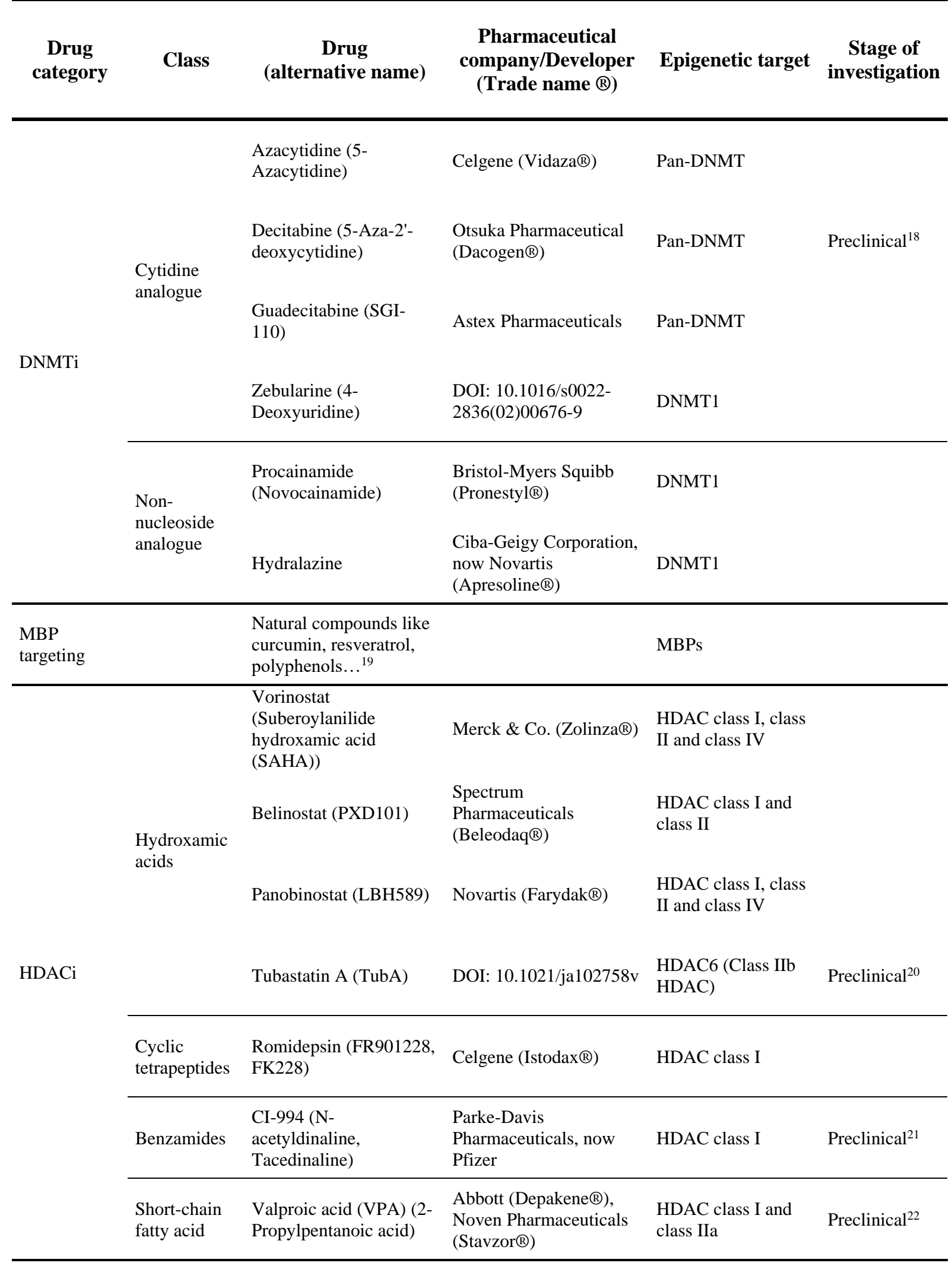




\begin{tabular}{|c|c|c|c|c|}
\hline HMTi & GSK126 (GSK2816126) & GlaxoSmithKline & EZH2 & Preclinical $^{23}$ \\
\hline \multirow{3}{*}{ BETi } & JQ1 & $\begin{array}{l}\text { DOI: } \\
\text { 10.1038/nature09504 }\end{array}$ & Pan-BET & \\
\hline & OTX015 (MK-8628) & Merck \& Co. & Pan-BET & \\
\hline & I-BET762 (GSK525762) & GlaxoSmithKline & Pan-BET & \\
\hline $\begin{array}{l}\text { Epigenetic } \\
\text { modifier } \\
\text { degradation }\end{array}$ & \multicolumn{2}{|l|}{$\begin{array}{l}\text { Small-molecule } \\
\text { PROTACs }^{24}\end{array}$} & $\begin{array}{l}\text { All epigenetic } \\
\text { modifiers and } \\
\text { readers }\end{array}$ & \\
\hline \multicolumn{5}{|c|}{$\begin{array}{l}\text { AF, atrial fibrillation; BET, bromodomain and extra-terminal motif; BETi, BET inhibitor; } \\
\text { DNMT, DNA methyltransferase; DNMTi, DNMT inhibitor; EZH2, enhancer of zeste 2; } \\
\text { HDAC, histone deacetylase; HDACi, HDAC inhibitor; HMTi, histone methyltransferase } \\
\text { inhibitor; MBP, methyl-CpG binding protein; PROTAC, proteolysis targeting chimeric. }\end{array}$} \\
\hline
\end{tabular}




\section{References}

1. Lu Y, Zhang Y, Wang N, et al. MicroRNA-328 contributes to adverse electrical remodeling in atrial fibrillation. Circulation 2010;122:2378-2387.

2. Xiao J, Liang D, Zhang Y, et al. MicroRNA expression signature in atrial fibrillation with mitral stenosis. Physiol Genomics 2011;43:655-664.

3. Cooley N, Cowley MJ, Lin RCY, et al. Influence of atrial fibrillation on microRNA expression profiles in left and right atria from patients with valvular heart disease. Physiol Genomics 2012;44:211-219.

4. Liu Z, Zhou C, Liu Y, et al. The expression levels of plasma micoRNAs in atrial fibrillation patients. PLoS One 2012;7:e44906.

5. $\quad$ Ling T-Y, Wang X-L, Chai Q, et al. Regulation of the SK3 channel by microRNA-499-potential role in atrial fibrillation. Heart Rhythm 2013;10:1001-1009.

6. Nishi H, Sakaguchi T, Miyagawa S, et al. Impact of microRNA expression in human atrial tissue in patients with atrial fibrillation undergoing cardiac surgery. PLoS One 2013;8:e73397.

7. McManus DD, Lin H, Tanriverdi K, et al. Relations between circulating microRNAs and atrial fibrillation: data from the Framingham Offspring Study. Heart Rhythm 2014;11:663-669.

8. Liu H, Chen G-X, Liang M-y, et al. Atrial fibrillation alters the microRNA expression profiles of the left atria of patients with mitral stenosis. BMC cardiovasc disord $2014 ; 14: 10$.

9. Goren Y, Meiri E, Hogan C, et al. Relation of reduced expression of MiR-150 in platelets to atrial fibrillation in patients with chronic systolic heart failure. Am J Cardiol 2014;113:976-981. 
10. Liu H, Qin H, Chen G-x, et al. Comparative expression profiles of microRNA in left and right atrial appendages from patients with rheumatic mitral valve disease exhibiting sinus rhythm or atrial fibrillation. J Transl Med 2014;12:90.

11. Slagsvold KH, Johnsen AB, Rognmo O, Hoydal MA, Wisloff U, Wahba A. Mitochondrial respiration and microRNA expression in right and left atrium of patients with atrial fibrillation. Physiol Genomics 2014;46:505-511.

12. Slagsvold KH, Johnsen AB, Rognmo O, Høydal M, Wisløff U, Wahba A. Comparison of left versus right atrial myocardium in patients with sinus rhythm or atrial fibrillation - an assessment of mitochondrial function and microRNA expression. Physiol Rep $2014 ; 2$.

13. McManus DD, Tanriverdi $\mathrm{K}$, Lin $\mathrm{H}$, et al. Plasma microRNAs are associated with atrial fibrillation and change after catheter ablation (the miRhythm study). Heart Rhythm 2015;12:3-10.

14. Lu Y, Hou S, Huang D, et al. Expression profile analysis of circulating microRNAs and their effects on ion channels in Chinese atrial fibrillation patients. Int J Clin Exp Med $2015 ; 8: 845-853$.

15. Wang J, Song S, Xie C, et al. MicroRNA profiling in the left atrium in patients with non-valvular paroxysmal atrial fibrillation. BMC cardiovasc disord 2015;15:97.

16. Doñate Puertas R, Jalabert A, Meugnier E, Euthine V, Chevalier P, Rome S. Analysis of the microRNA signature in left atrium from patients with valvular heart disease reveals their implications in atrial fibrillation. PLoS One 2018;13:e0196666.

17. Kiliszek M, Maciak K, Maciejak A, et al. Serum microRNA in patients undergoing atrial fibrillation ablation. Sci Rep 2020;10:4424. 
18. Doñate Puertas R, Meugnier E, Romestaing C, et al. Atrial fibrillation is associated with hypermethylation in human left atrium, and treatment with decitabine reduces atrial tachyarrhythmias in spontaneously hypertensive rats. Transl Res 2017;184:57-67.e55.

19. Mahmood N, Rabbani SA. DNA Methylation Readers and Cancer: Mechanistic and Therapeutic Applications. Front Oncol 2019;9:489.

20. Zhang D, Wu CT, Qi X, et al. Activation of histone deacetylase-6 induces contractile dysfunction through derailment of alpha-tubulin proteostasis in experimental and human atrial fibrillation. Circulation 2014;129:346-358.

21. Seki M, LaCanna R, Powers JC, et al. Class I Histone Deacetylase Inhibition for the Treatment of Sustained Atrial Fibrillation. J Pharmacol Exp Ther 2016;358:441-449.

22. Scholz B, Schulte JS, Hamer S, et al. HDAC (Histone Deacetylase) Inhibitor Valproic Acid Attenuates Atrial Remodeling and Delays the Onset of Atrial Fibrillation in Mice. Circ Arrhythm Electrophysiol 2019;12:e007071.

23. Song S, Zhang R, Mo B, et al. EZH2 as a novel therapeutic target for atrial fibrosis and atrial fibrillation. J Mol Cell Cardiol 2019;135:119-133.

24. Sun X, Gao H, Yang Y, et al. PROTACs: great opportunities for academia and industry. Signal Transduct Target Ther 2019;4:64. 